\title{
Organic dyes as corrosion inhibitors of commercial AA1050 aluminum alloy in sodium chloride environment
}

\author{
Paraskevi Pantazopoulou $^{1 *}$, Stamatina Theohari ${ }^{2}$ and Sofia Kalogeropoulou ${ }^{1}$ \\ ${ }^{1}$ Department of Electrical and Electronic Engineering, University of West Attica \\ ${ }^{2}$ Graphic Design and Visual Communication Department, University of West Attica
}

\begin{abstract}
Considering corrosion control of aluminum is of great technical, economic, environmental and aesthetical importance, the use of inhibitors is one of the promising solutions for protecting aluminum and its alloys against corrosion. The research about green corrosion inhibitors which are environmentally friendly and do not contain heavy metals or other toxic compounds has gained a large interest. This study is an effort to investigate the role of a natural organic dye, Crocin, against the corrosion of a commercial aluminum alloy AA1050, in an aggressive chloride ions environment of $\mathrm{NaCl} 0,01 \mathrm{M}$, in comparison with a synthetic dye, Alphazurine A. Corrosion behavior of AA1050 specimens in $\mathrm{NaCl} 0,01 \mathrm{M}$ solution at room temperature was studied by investigating their electrochemical behavior in the absence and presence of the two organic dyes, using DC Corrosion techniques, Linear Polarization and Tafel Polarization. The effect of the organic dyes as corrosion inhibitors was also evaluated by mass loss measurements. Study and characterization of the morphology of the surface of the specimens, before and after the corrosion measurements, was performed using Scanning Electron Microscopy. Results obtained showed that the examined dyes have a protective action against corrosion of aluminum surface in the corrosive environment.
\end{abstract}

\section{Introduction}

The use of aluminum alloys is of continuous interest in numerous applications because of their properties: Aluminum is abundant and has relatively low price, high strength to weight ratio, superb thermal and electrical conductivity. It is also nonferromagnetic, nonpyrophoric, non-toxic, can be fabricated into any form, is $95 \%$ recyclable and it is resistant to corrosion (except in acidic, alkaline or chloride-containing solutions) as a result of the formation of a passive oxide layer on its surface. Various applications include automotive and aerospace industry, marine constructions, construction of machines, appliances, and structures, cooking utensils, covers for housings for electronic equipment, pressure vessels for cryogenic applications, etc. $[1,2]$.

\footnotetext{
* Corresponding author: parpant $@$ uniwa.gr
} 
Corrosion control of aluminum is of great technical, economic, environmental and aesthetical significance. Although a protective passive oxide film is possible to be formed naturally, chemically or electrolytically on the aluminum surface, pitting corrosion of aluminum takes place in chloride solutions. Pitting corrosion is the most hazardous form of aluminum corrosion. It appears as holes and pits of irregular shapes on the surface of the metal. This is a continuous and constant problem, frequently arduous to eliminate entirely, since it depends on various factors, such as the composition and the properties of the alloy, the aluminum surface morphology, as well as the local environment, such as the changes in $\mathrm{pH}$ and temperature values and the composition of the corrosive solution [3-5].

In chloride solution, chloride ions attack the natural oxide layer, damaging it in its weakest parts. On the anodic sites, anodic dissolution of aluminum happens, forming aluminum chloride, which hydrolyzes to form aluminum hydroxide and acid, so an acidic environment is created. The cathodic sites are alkaline due to the hydroxide formation $[6,7]$ :

Anodic reactions: $\mathrm{Al} \rightleftarrows \mathrm{Al}^{3+}+3 \mathrm{e}$

$\mathrm{AlCl}_{3}+3 \mathrm{H}_{2} \mathrm{O} \rightleftarrows \mathrm{Al}(\mathrm{OH})_{3}+\mathrm{HCl}$

Cathodic reactions: $3 \mathrm{H}^{+}+3 \mathrm{e} \rightleftarrows 3 / 2 \mathrm{H}_{2}$

$$
1 / 2 \mathrm{O}_{2}+\mathrm{H}_{2} \mathrm{O}+2 \mathrm{e} \rightleftarrows 2 \mathrm{OH}^{-}
$$

The use of corrosion inhibitors is a widespread method for protecting aluminum from pitting corrosion. Organic compounds containing polar groups have been researched as inhibitors. Organic dyes have been stated to act as corrosion inhibitors with high inhibition efficiencies due to their adsorption onto the metal surface, but their use may cause adverse effects on human beings and the environment. Eco-friendly substances and natural products of plant origin are investigated as corrosion inhibitors and have been found to exhibit good inhibition efficiencies [8-11]. Crocin, a natural product from the Greek plant crocus sativus, could be a promising corrosion inhibitor for aluminum [12].

This study is an effort to investigate the role of a natural organic dye, Crocin, against the corrosion of a commercial aluminum alloy AA1050, in an aggressive chloride ions environment of $\mathrm{NaCl} 0,01 \mathrm{M}$, in comparison with a synthetic dye, Alphazurine A, which has already shown a protective anticorrosive action $[13,14]$.

\section{Experimental}

\subsection{Materials}

As corrosion inhibitors, Crocin and Alphazurine A were used. Crocin is a natural carotenoid chemical compound that exists in the crocus flower and primarily responsible for the colour of saffron (Natural Yellow 6, C.I. 75100, Mr 976,96). Alphazurine A is a thriphenylmethane synthetic dye which has already shown a protective anticorrosive action (Acid Blue 7, C.I. 42080, Mr 690,82) [13, 14]

(a)

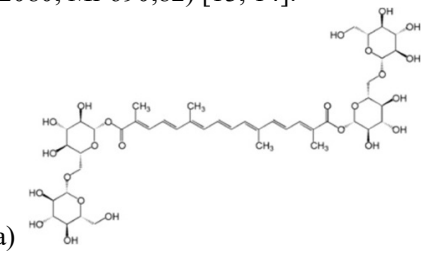

(b)

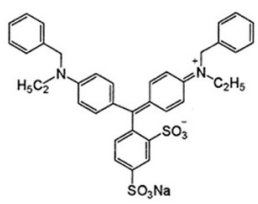

Fig. 1. Structure of corrosion inhibitors: (a) Crocetin digentiobiose ester $\mathrm{C}_{44} \mathrm{H}_{64} \mathrm{O}_{24}$, (b) Alphazurine $\mathrm{A} \mathrm{C}_{37} \mathrm{H}_{35} \mathrm{~N}_{2} \mathrm{NaO}_{6} \mathrm{~S}_{2}$. 
The following concentrations of Crocin and Alphazurine $\mathrm{A}$ in the $\mathrm{NaCl}$ solution were studied.

Table 1. Test solutions

\begin{tabular}{|c|c|}
\hline Solution & Name \\
\hline $0,01 \mathrm{M} \mathrm{NaCl}$ (Reference) & $\mathrm{R}$ \\
\hline $0,01 \mathrm{M} \mathrm{NaCl}+0,025 \mathrm{mM}$ Crocin & $\mathrm{Cr} 0,025$ \\
\hline $0,01 \mathrm{M} \mathrm{NaCl}+0,25 \mathrm{mM}$ Crocin & $\mathrm{Cr} 0,25$ \\
\hline $0,01 \mathrm{M} \mathrm{NaCl}+1,25 \mathrm{mM}$ Crocin & $\mathrm{Cr} 1,25$ \\
\hline $0,01 \mathrm{M} \mathrm{NaCl}+1,5 \mathrm{mM}$ Crocin & $\mathrm{Cr} 1,5$ \\
\hline $0,01 \mathrm{M} \mathrm{NaCl}+1,25 \mathrm{mM}$ Alphazurine A & $\mathrm{AZ} 1,25$ \\
\hline
\end{tabular}

AA 1050 aluminum test specimens for the electrochemical measurements were cut into $50 \mathrm{mmX} 75 \mathrm{mmX} 1 \mathrm{~mm}$ coupons and mechanically polished with emery papers of 600,800 , 1000 and 1200 grades. Then the coupons were degreased using acetone, rinsed with deionized water, dried in air and stored in desiccators before usage. Test specimens for the mass loss measurements were cut into $20 \mathrm{mmX} 20 \mathrm{mmX} 1 \mathrm{~mm}$ coupons.

Table 2. Composition (wt. \%) of 1050 aluminum samples.

\begin{tabular}{|c|c|c|c|c|c|c|c|c|c|}
\hline Elements & $\mathrm{Al}$ & $\mathrm{Si}$ & $\mathrm{Fe}$ & $\mathrm{Mn}$ & $\mathrm{Mg}$ & $\mathrm{Cu}$ & $\mathrm{Ti}$ & $\mathrm{Cr}$ & $\mathrm{Zn}$ \\
\hline $\mathbf{1 0 5 0}($ H14) & $>99$ & 0,168 & 0,245 & 0,003 & 0,001 & 0,001 & 0,006 & 0,002 & 0,013 \\
\hline
\end{tabular}

\subsection{Experimental techniques}

Electrochemical techniques: With the intention of studying the corrosion behavior of the AA1050 specimens in the $\mathrm{NaCl} 0,01 \mathrm{M}$ solution at room temperature, their electrochemical behavior was investigated in the absence and presence of the two organic dyes, using DC Corrosion techniques, Linear Polarization and Tafel Polarization. A Gamry Interface 1000 Potentiostat/Galvanostat/ZRA controlled by a Gamry Framework electrochemical program was used to perform the electrochemical measurements with the aid of DC105 Corrosion Techniques Software. The working electrode was the aluminum specimen, exhibiting an exposed surface area equal to $1 \mathrm{~cm}^{2}$, the reference electrode was $\mathrm{Ag} / \mathrm{AgCl}$ and the counter electrode was Pt. Measurements were performed at ambient temperature with the electrolyte in contact with air. Before each measurement the specimen was kept at open circuit and the change of the potential was recorded for one hour (Open Circuit Potential). Polarization Resistance (RP) was calculated from Linear Polarization Scan at a scan rate of $0,125 \mathrm{mV} / \mathrm{s}$ and a potential range of $\pm 0,02 \mathrm{~V}$ vs. OCP. Tafel Scan was performed at a scan rate of 0,166 $\mathrm{mV} / \mathrm{s}$ and a potential range of $-0,250 \mathrm{~V}$ to $+0,400 \mathrm{~V}$ vs. OCP.

Mass loss measurements: Specimens were kept in test solutions at room temperature for 6 weeks. Initially, test specimens were cleaned with acetone and weighed for the original mass. Samples were taken out from the solutions weekly, rinsed with deionized water, immersed in nitric acid $\left(\mathrm{HNO}_{3}\right)$ to remove corrosion products, rinsed again with deionized water, 
cleaned with acetone, dried and weighed in order to obtain the final mass, according to ISO 8407.

Study and characterization of the morphology of the specimens' surface: Scanning Electron Microscopy (SEM), equipped with Energy Dispersive Spectroscopy (EDS) (A Scanning Electron Microscopy JEOL JSM-6510 LV - EDAX (Oxford Instruments, 10 $\mathrm{mm}^{2}$ Silicon Drift Detector - $\mathrm{x}$ - act) was utilised for observation and analysis.

\section{Results}

Time dependence of the Open Circuit Potential of aluminum specimens immersed in the reference solution of $0,01 \mathrm{M} \mathrm{NaCl}$ as well as in solutions with $0,01 \mathrm{M} \mathrm{NaCl}$ and various concentrations of Crocin is given in Fig.2. It is obvious in all cases that after one hour of exposure a virtually steady state condition is reached. Values of OCP for the reference specimen are in the region of -690 to $-680 \mathrm{mV}$, whereas for specimens in three Crocin solutions values are more positive in the region of -630 to $-610 \mathrm{mV}$ and for the $\mathrm{Cr} 1,25$ solution $-590 \mathrm{mV}$. The differences in the OCP values lead to a qualitative estimation of the tendency of the corrosion activity of the samples. Consequently, specimens in the CR1,25 solution exhibit the lowest corrosion tendency, which means that their behaviour is better than that of specimens in the other three Crocin solutions, as compared to reference specimens, that show the greater tendency for corrosion. This indicates an inhibiting effect of Crocin on the surface corrosion of AA1050 aluminum test specimens.

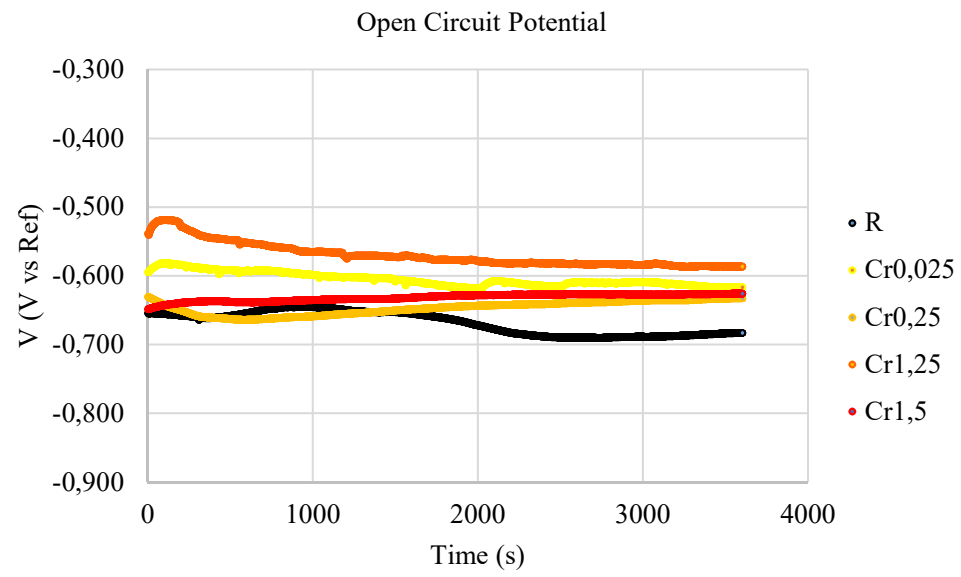

Fig. 2. Open Circuit Potential for 1050 aluminum test specimens immersed in solutions with $0,01 \mathrm{M} \mathrm{NaCl}$ and with $0,01 \mathrm{M} \mathrm{NaCl}$ and Crocin.

Polarization Resistance (PR) values of aluminum specimens immersed in the reference solution of $0,01 \mathrm{M} \mathrm{NaCl}$, in solutions with $0,01 \mathrm{M} \mathrm{NaCl}$ and various concentrations of Crocin and in solution with $0,01 \mathrm{M} \mathrm{NaCl}$ and Alphazurine A are given in Fig.3. Values for the $\mathrm{Cr} 1,25$ solution are almost five times greater than that of the reference solution, whereas all other solutions present PR values two to four times greater than the reference solution. It is obvious that all Crocin concentrations protect aluminum from corrosion, and the concentration of $1,25 \mathrm{mM}$ of Crocin presents the best results. 


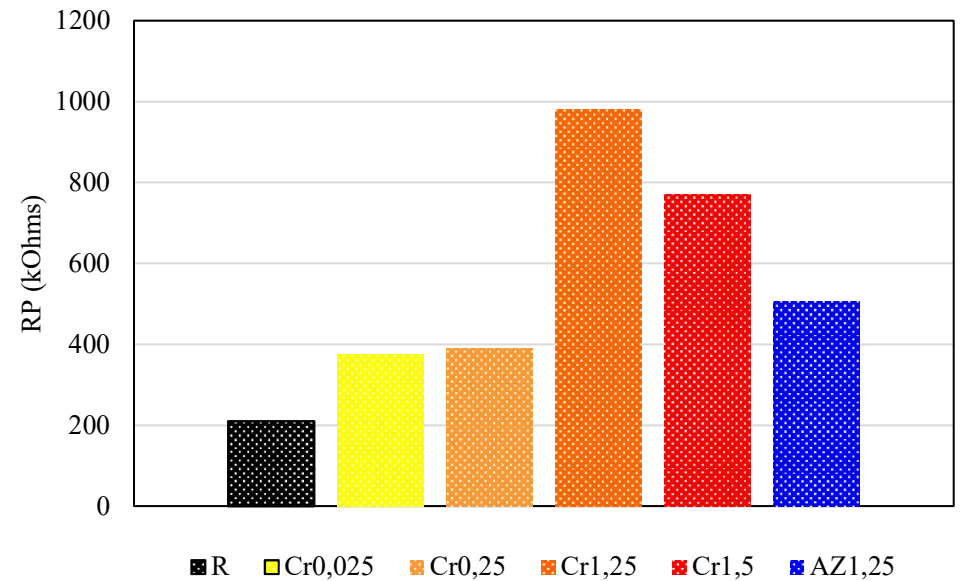

Fig. 3. Polarization Resistance values for aluminum test specimens immersed in all examined solutions.

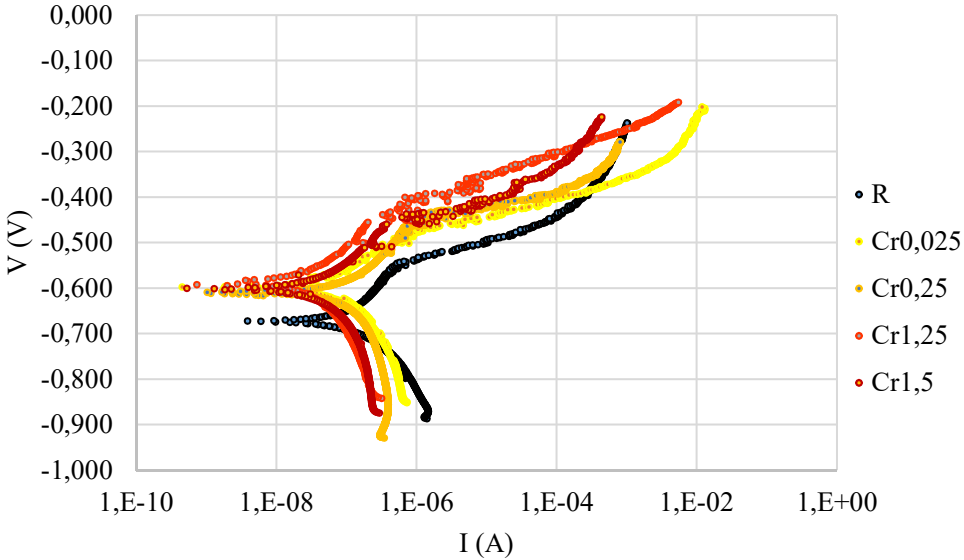

Fig. 4. Tafel Polarization curves for aluminum test specimens immersed in $0,01 \mathrm{M} \mathrm{NaCl}$ solutions, without and with Crocin at various concentrations.

Electrochemical parameters of aluminum specimens in all solutions obtained from Tafel polarization curves presented in Fig.4 are shown in Table 3. Values of corrosion potential of aluminum test specimens in all solutions are higher than the ones in the reference solution, indicating lower corrosion tendency due to the protection offered by the inhibitors. There is also a significant decrease in the anodic Tafel constant, suggesting that Crocin acts as an anodic inhibitor, impeding the formation of aluminum chloride. 
Table 3. Electrochemical parameters of aluminum specimens in test solutions

\begin{tabular}{|c|c|c|c|c|c|c|}
\hline & Ecorr(V) & Icorr(A) & ba(V/dec) & bc(V/dec) & CR (mpy) & Epit(V) \\
\hline $\mathbf{R}$ & $-0,671$ & $7,12 \mathrm{E}-07$ & 0,9317 & 0,4977 & $3,09 \mathrm{E}-01$ & $-0,540$ \\
\hline Cr0,025 & $-0,596$ & $2,19 \mathrm{E}-07$ & 0,3139 & 0,4666 & $9,40 \mathrm{E}-02$ & $-0,500$ \\
\hline $\mathbf{C r 0 , 2 5}$ & $-0,604$ & $1,96 \mathrm{E}-07$ & 0,2920 & 0,4560 & $8,49 \mathrm{E}-02$ & $-0,460$ \\
\hline $\mathbf{C r 1 , 2 5}$ & $-0,587$ & $7,44 \mathrm{E}-08$ & 0,2607 & 0,4500 & $3,19 \mathrm{E}-02$ & $-0,420$ \\
\hline $\mathbf{C r 1 , 5}$ & $-0,600$ & $1,17 \mathrm{E}-07$ & 0,2773 & 0,4921 & $5,01 \mathrm{E}-02$ & $-0,450$ \\
\hline $\mathbf{A Z 1 , 2 5}$ & $-0,616$ & $5,69 \mathrm{E}-08$ & 0,2494 & 0,2087 & $2,44 \mathrm{E}-02$ & $-0,400$ \\
\hline
\end{tabular}

The inhibition efficiency of solutions with Crocin and Alphazurine A derived from corrosion current, calculated from the equation: $\operatorname{IE}(\%)=\left[\left(\mathrm{I}_{\text {corr, } \mathrm{R}}-\mathrm{I}_{\text {corr }, \mathrm{S}}\right) / \mathrm{I}_{\text {corr }, \mathrm{R}}\right] \times 100$, where $\mathrm{I}_{\text {corr, } \mathrm{R}}$ and $\mathrm{i}_{\mathrm{corr}, \mathrm{S}}$ are the corrosion currents in the reference and in the inhibiting solution, respectively, is depicted in Fig. 5 [15]. All efficiencies are high, varying from $70 \%$ to $92 \%$. The highest values are present when the concentration of the inhibitor is $1,25 \mathrm{mM}$, either as Crocin or as Alphazurine A.

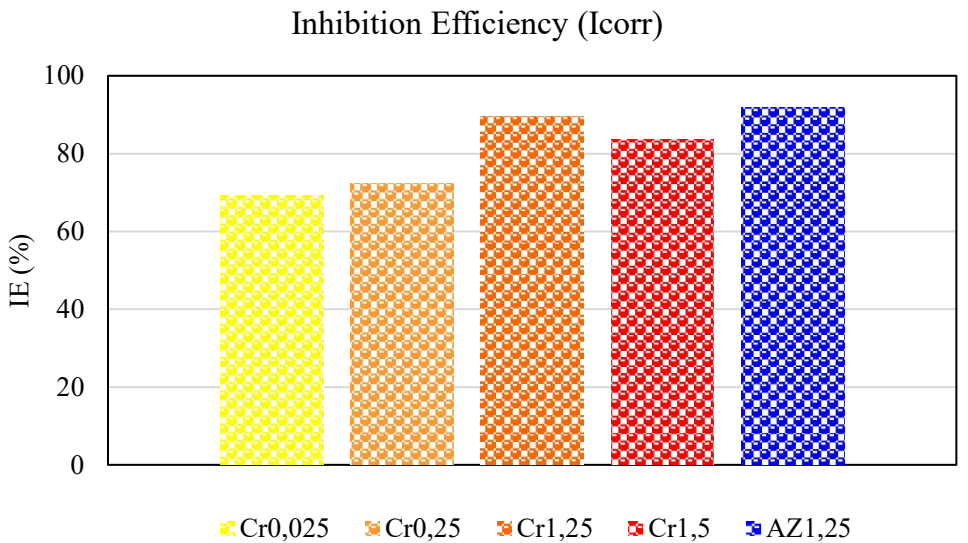

Fig. 5. Inhibition efficiency of test solutions derived from corrosion current.

The corrosion rate of aluminum test specimens was assessed by the mass loss measurements versus exposure time in $0,01 \mathrm{M} \mathrm{NaCl}$ solution. The results of these measurements after six weeks of exposure are given in Fig.6. The enhancement of the corrosion performance of aluminum when both inhibitors, Crocin or Alphazurine A, at a concentration of $1,25 \mathrm{mM}$ are added in the solutions is evident, since mass loss in these solutions is almost six times less than in the reference solution. The respective inhibition efficiency of solutions $\mathrm{Cr} 1,25$ and AZ1,25 derived from mass loss measurements achieve percentages of $95-97 \%$, thus exhibiting a superior performance. 


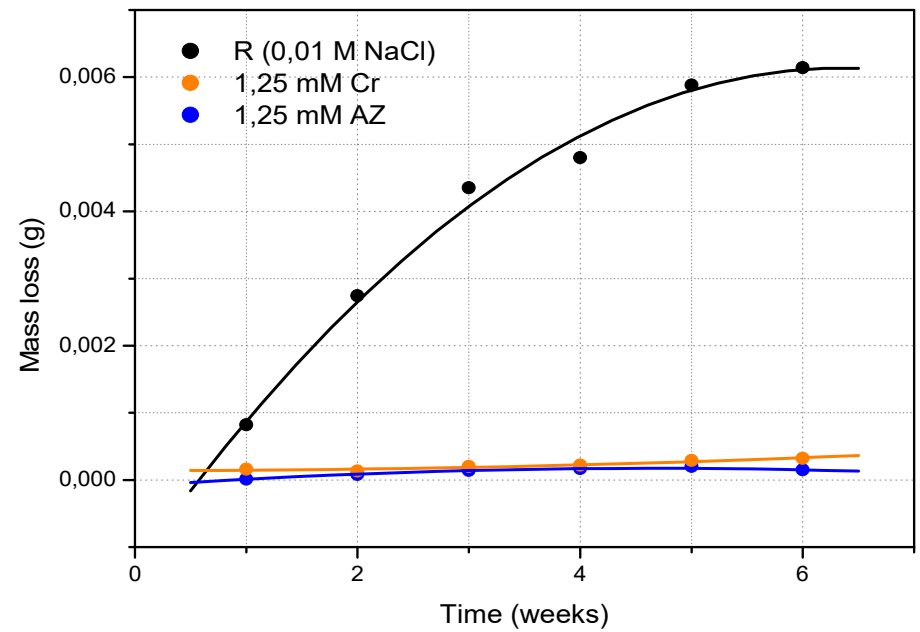

Fig. 6. Mass loss measurements versus exposure time.

Surface morphology of samples, before and after corrosion experiments was investigated by SEM/EDS. Pictures of all specimens at a magnification of 60 times are presented in Fig.7. The beneficial effect of inhibitors is apparent, since as the concentration of Crocin increases, less corrosion signs are present. At concentrations of $1,25 \mathrm{mM}$ and $1,5 \mathrm{mM}$ the aluminum surface is smoother, without spots of localized pitting corrosion. The same applies for the solution of $1,25 \mathrm{mM}$ Alphazurine A. These results are in accordance with the ones from the electrochemical corrosion testing and the mass loss measurements.

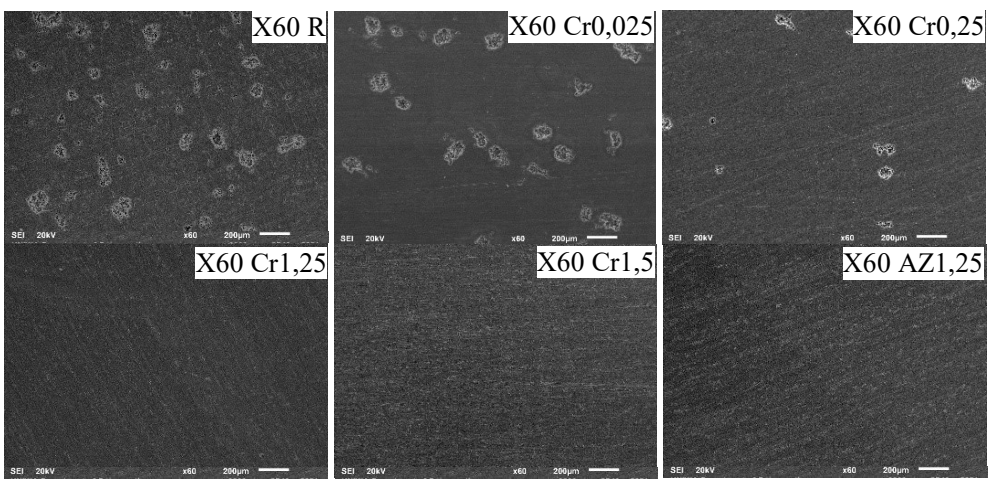

Fig. 7. SEM micrographs (X60) of AA1050 aluminum surface specimens after polarization tests. 


\section{Conclusions}

- The addition of Crocin in the sodium chloride corrosive solution leads to more positive values of corrosion potential, lower values of corrosion current and lower values of corrosion rate, indicating an inhibiting effect on the surface corrosion of AA1050 aluminum test specimens.

- The increase in inhibitor concentration improves the corrosion resistance of the specimens, and the best behaviour is observed with the $1,25 \mathrm{mM}$ of Crocin, which is comparatively similar to the one observed by Alphazurine at the same concentration.

- The inhibition efficiency of Crocin can be attributed to chemisorption or adsorption of -OH groups of the Crocin molecule by forming an isolation protective layer on the aluminum surface.

- These results are in conformity with the mass loss results and the morphology of the specimens' surface observed by Scanning Electron Microscopy.

\section{References}

1. J.R. Davis, Alloying: Understanding the Basics, ASM International, 351 (2001)

2. E. Canepa, R. Stifanese, L. Merotto, P. Traverso, Mar. Struct. 59, 271 (2018)

3. F-Y. Ma, Corrosive Effects of Chlorides on Metals, Pitting Corrosion, ed. N.Bensahah, Intech, 139 (2012)

4. H. Ezuber, A. El-Houd, F. El-Shawesh, Mater. Des. 29, 801 (2008)

5. M. Witkowska, G.E. Thompson, T. Hashimoto, E. Koroleva, Surf. Interface Anal. 45, 1585 (2013)

6. K. Xhanari, M. Finsgar, Arabian Journal of Chemistry 12, 4646 (2019)

7. P. M. Natishan, W. E. O’Grady, J. Electrochem. Soc. 161(9) C421 (2014)

8. R. Solmaz, G. Kardaş, B. Yazıcı, M. Erbil, Corros. Eng. Sci. Technol. 43(2), 186 (2008)

9. K. Zhang, W. Yang, B. Xu, Y. Chen, X. Yin, Y. Liu, H. Zuo, J. Colloid Interface Sci. $\mathbf{5 1 7}, 52(2018)$

10. C. Verma, E.E. Ebenso, I. Bahadur, M.A. Quraishi, J. Mol. Liq. 266, 577 (2018)

11. M. Sangeetha, S. Rajendran, J. Sathiyabamaa, A. Krishnavenic, Port. Electrochim. Acta 31(1), 41 (2013)

12. T.Y. Soror, Eur. Chem. Bull. 2(4) 191 (2013)

13. I. Tsangaraki, A. Kanta, S. Theohari, Anti-Corros Method M, 57, 1 (2010)

14. S. Theohari, A. Kanta, I. Tsangaraki, Chemical etching of aluminum as a pretreatment improving the anti-corrosive properties of certain organic compounds, in Proc. of the $4^{\text {th }}$ International Conference of Engineering Against Failure, Skiathos, Greece (2015)

15. A.Y. El-Etre, Corros. Sci., 45(11), 2485 (2003)

This research is co-financed by Greece and the European Union (European Social Fund- ESF) through the Operational Programme «Human Resources Development, Education and Lifelong Learning» in the context of the project "Reinforcement of Postdoctoral Researchers - 2nd Cycle" (MIS-5033021), implemented by the State Scholarships Foundation (IKY).

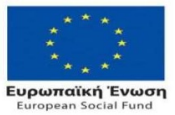

